Informatio: Journal of Library and Information Science Vol. 1(1), 1-16, Januari 2021

ISSN 2775-0043 (Online)

\title{
Hubungan knowledge sharing dengan inovasi pengelola taman baca masyarakat di Jawa Barat
}

\author{
Yoshua Gilang Pratama ${ }^{a^{*}}$, Sukaesih ${ }^{\mathrm{b}}$, Samson CMS \\ ${ }^{a}$ Farianto \& Darmanto Law Firm Jakarta \\ bcFakultas Ilmu Komunikasi Universitas Padjadjaran Bandung
}

\begin{abstract}
Abstrak
Dunia dihadapkan dengan fenomena hypercompetition, di mana cara kerja diharuskan berubah menjadi lebih dinamis dan modern. Fenomena ini mencakup ke semua aspek, termasuk dunia perpustakaan dan literasi Indonesia. Berhadapan dengan masalah yang baru, dunia perpustakaan dan literasi Indonesia juga sebenarnya masih berusaha menyelesaikan masalah lamanya, yaitu rendahnya tingkat literasi Indonesia. Taman Baca Masyarakat (TBM) hadir dengan tujuan untuk mengingkatkan tingkat literasi Indonesia. Namun banyak TBM yang baru didirikan cenderung bersifat statis dan tradisional, yang mana sudah tidak relevan dengan zaman. Forum Taman Baca Masyarakat Jawa Barat (FTBM Jawa Barat) hadir guna membantu TBM supaya bisa tetap relevan dengan zaman. Dalam kegiatannya, FTBM Jawa Barat menerapkan Knowledge Management secara umum dan Knowledge Sharing secara khusus. Penelitian ini mengkaji tentang peran Knowledge Sharing dan seberapa besar hubungannya terhadap inovasi pengelola TBM. Knowledge Sharing sendiri memiliki dua dimensi, yaitu; Knowledge Donating dan Knowledge Collecting. Populasi dari penelitian ini adalah FTBM Jawa Barat, dengan sampel berjumlah 67 orang pengelola TBM. Metode yang digunakan adalah kuantitatif dengan analisis korelasional, pengujian hipotesisnya mengujikan Knowledge Donating, Collecting, dan Sharing dengan Inovasi Pengelola. Hasil penelitian Knowledge Donating, Collecting, dan Sharing masingmasing mempunyai hubungan dengan Inovasi Pengelola, dengan koefisien determinasinya, secara berurutan, sebesar 17,47\%; 20,88\%; dan 27,66\%. Hal ini menunjukkan bahwa Inovasi Pengelola di FTBM Jawa Barat tidak tercipta semata-mata karena adanya Knowledge Sharing, banyak faktor lainnya yang memengaruhi, salah satunya adalah lamanya pengalaman seseorang dalam mengelola TBM. Kedepannya, pelaksanaan Knowledge Sharing di FTBM Jawa Barat diharapkan lebih dinamis lagi, dengan memperluas referensi hal yang diinovasikan dan kolaborasi dengan komunitas lain di luar komunitas literasi, hal ini agar menambah sudut pandang baru Pengelola TBM di FTBM Jawa Barat.
\end{abstract}

Kata kunci: Knowledge sharing, Knowledge donating, Knowledge collecting, Inovasi; TBM

Korespondensi: Yoshua Gilang Pratama, Soho Pancoran, Noble wing 1102, Jl. Letjen M.T. Haryono No. Kav. 2-3, Rt.3/Rw.1, Cikoko, Kec. Pancoran, Kota Jakarta Selatan, Daerah Khusus Ibukota Jakarta 12770, Indonesia

Email: yoshua@fardalaw.com

http://jurnal.unpad.ac.id/informatio

DOI: https://doi.org/10.24198/inf.v1i1.30708

Received: November 2020; Accepted: Januari 2021; Published: Januari 2021

(C) Informatio 2021. This is an open access article under the CC BY-SA license 


\title{
The relation between knowledge sharing and reading park forum's manager innovation in West Java
}

\begin{abstract}
The world is now facing the phenomenon of hypercompetition, where working procedure is required to change to be more dynamic and modern. This phenomenon covers all aspects, including Indonesian library world and Indonesian literacy. Faced with new problems, Indonesian library world and Indonesian literacy has actually been trying to solve its old issue: the low level of Indonesian literacy. Community Reading Park (TBM) exists with the aim of increasing the level of Indonesian literacy. However, many newly established TBMs tend to be static and traditional, which are no longer relevant to modern times. West Java Community Reading Park Forum (West Java FTBM) is present to help TBMs stay relevant with present situation. In its activities, West Java FTBM applies Knowledge Management in general and Knowledge Sharing in particular. This study examines the role of Knowledge Sharing and how much it relates to innovation in TBM managers. Knowledge Sharing itself has two dimensions, namely; Knowledge Donating and Knowledge Collecting. The population in this study was West Java FTBM, with a sample of 67 TBM managers. The method used was quantitative with correlational analysis, and hypotheses testing was done by testing Knowledge Donating, Collecting, and Sharing with Manager's Innovations. The research results of Knowledge Donating, Collecting, and Sharing each had relationship with Manager's Innovation, with the coefficient of determination, sequentially, 17.47\%; 20.88\%; and 27.66\%. This shows that Manager's Innovation in West Java FTBM was not created solely because of Knowledge Sharing, but many other factors affected it, one of which is the length of one's experience in managing TBM. In the future, the implementation of Knowledge Sharing in West Java FTBM is expected to be even more dynamic by expanding references to things innovated and collaborating with other communities, this is to add a new point of view for TBM Managers in West Java FTBM
\end{abstract}

Keywords: Knowledge sharing; Knowledge donating; Knowledge collecting; Innovation; TBM

\section{PENDAHULUAN}

TBM (Taman Baca Masyarakat) merupakan sebuah organisasi/program yang memiliki latar belakang yang cukup panjang. Hal ini bermula dengan didirikannya Taman Pustaka Rakyat (TPR) pada tahun 1950-an oleh Pendidikan Masyarakat yang kemudian dilakukan pembaharuan melalui program Taman Baca Masyarakat (TBM) pada tahun 1992/1993, (Suwanto 2019). TBM dibuat dengan tujuan untuk menanamkan budaya membaca yang sekaligus untuk meningkatkan tingkat literasi masyarakat Indonesia. TBM di Indonesia dapat dibaratkan dengan tumbuhan musiman yang terus tumbuh dan tumbang seiring dengan berjalannya waktu. Pertumbuhan TBM pada umumnya dilandasi dengan kepedulian beberapa pihak yang ingin menumbuhkan minat belajar. Tumbangnya sebuah TBM lebih sering dikarenakan alasan krisis pengelolaan. Meskipun tumbuh dan tumbang secara berganti, TBM tetap berpegang teguh pada tujuannya, dan terus melakukan aktivitas organisasinya.

Puluhan tahun lamanya berdiri, TBM tentu saja memiliki banyak masalah yang menghadang pada proses perkembangannya. Salah satunya adalah apa yang peneliti 
temukan di Kemah Literasi Jawa Barat tahun 2019, yaitu masih banyak pengelola TBM yang memiliki mindset statis dan tradisional. Mindset statis dan tradisional adalah pola pikir pengelola TBM, cara mereka mendapatkan sumbangan buku, target permohonan hibah buku, dan cara mengajak masyarakat untuk mau membaca, bukan belajar, tapi hanya membaca secara umum. Padahal dunia sudah dihadapkan dengan fenomena hypercompetition. Menurut Johannessen et al. (1999), fenomena ini mengartikan bahwa kita hidup di zaman di mana keunggulan bukanlah sesuatu yang mutlak, keunggulan hanya berlaku untuk waktu yang singkat saja, dikarenakan berbagai macam gangguan dan keadaan. Fenomena ini tentu saja mengubah cara kerja dunia secara drastis, dunia yang tadinya berpegang pada cara kerja yang statis dan tradisional berubah menjadi dinamis dan modern. Perubahan cara kerja dunia umumnya dan yang paling terlihat dampaknya, ada pada dunia bisnis, namun suka tidak suka dunia perpustakaan dan literasi pun dituntut untuk berubah mengikuti perubahan cara kerja dunia, menjadi dinamis dan modern.

Menurut Miller dan McKenna (2016) TBM dan pengelolanya dihadapkan dengan fakta bahwa Indonesia menduduki peringkat ke-60 dari 61 negara yang hanya mengungguli Botswana di peringkat ke-61 dalam hal gemar belajar. Kenyataan ini merupakan hal yang kontradiktif mengingat usaha TBM untuk menanamkan budaya membaca yang sekaligus untuk meningkatkan tingkat literasi masyarakat Indonesia, menghasilkan "rapor merah". Salah satu penyebab "rapor merah" itu bisa jadi karena mindset statis dan tradisional yang salah mengartikan apa itu TBM dan aktivitas yang bisa dilakukannya. TBM tidak hanya sebagai tempat buku saja, TBM berkembang sebagai pusat kreasi dan munculnya ide-ide baru yang ada di masyarakat dalam mewujudkan minat baca dan literasi di masyarakat (Pramudyo et al., 2018). TBM berusaha untuk memberikan layanan dan memenuhi kebutuhan bacaan masyarakat dengan menyediakan koleksi serta kegiatan-kegiatan untuk meningkatan wawasan masyarakat. Untuk mewujudkan peran TBM, TBM harus terus berupaya melakukan inovasi kegiatan secara aktif (Pramudyo et al., 2018).

TBM yang merupakan sebuah organisasi, dituntut untuk mampu menstimulus sikap inovatif dari anggota organisasinya, dalam hal ini para pengurus dan pengguna TBM itu sendiri. Proses inovasi mengharuskan anggota organisasi memiliki ide-ide segar yang terus mengalir secepat mungkin yang didapat dari proses bertukar pikiran, berbagi pengalaman, dan kegiatan berbagi pengetahuan lainnya (Firmaiansyah, 2014). Hal ini mengartikan bahwa dalam mewujudkan peran TBM yang optimal di masyarakat, diperlukan TBM yang dapat berinovasi dalam kegiatannya, dan inovasi bisa didapatkan melalui kegiatan berbagi pengetahuan atau Knowledge Sharing. Hal tersebut didukung dengan teori dari Plessis (2007). Asumsi dari teori ini adalah knowledge management membantu menciptakan 
peralatan, rencana kerja, dan proses untuk tacit knowledge creation, sharing dan leverage yang berperan penting dalam proses inovasi. Adanya penerapan knowledge management secara umum dan knowledge sharing secara khusus diharapkan bisa membantu TBM mengatasi fenomena hypercompetition, membuat TBM beralih ke cara kerja yang lebih dinamis dan modern.

TBM tentunya tidak bergerak secara individual dalam usaha mengatasi masalah lama yaitu tingkat literasi Indonesia yang rendah, dan masalah baru yaitu fenomena hypercompetition. Pegiat literasi yang memiliki pengetahuan dan keahlian di bidangnya, mendirikan gerakan kolektif dalam bentuk forum yang bernama Forum Taman Baca Masyarakat. Forum ini dibagi menjadi beberapa tingkatan, mulai dari tingkat nasional, provinsi, sampai tingkat kabupaten/kota. Salah satunya adalah kepengurusan Provinsi Jawa Barat, yang mulai berkegiatan dari tahun 2006, dengan Forum Taman Baca Masyarakat Jawa Barat-nya, yang kemudian disingkat menjadi FTBM Jawa Barat. Adanya forum ini, memungkinkan pengelola Taman Baca Masyarakat di Jawa Barat untuk berkomunikasi dan berjejaring secara lebih intens. Pengelola TBM juga aktif dalam membagikan pengetahuan mereka, seperti; pengalaman, informasi, atau berita seputar literasi di forum ini. Sampai terciptalah sebuah acara besar dari FTBM Jawa Barat benama Kemah Literasi Jawa Barat, yang sudah dilakukan sebanyak dua kali, yaitu tahun 2017 dan 2019.

FTBM Jawa Barat sendiri sudah menerapkan knowledge management secara umum dan knowledge sharing secara khusus di dalam kegiatannya. Hal ini tercermin dari dibentuknya grup di berbagai macam platform sebagai sarana berbagi pengetahuan, sebuah website dengan tim redaksi yang siap membuat dan mempublikasikan berita, serta acara besar yaitu Kemah Literasi Jawa Barat yang memungkinkan inovasi dan pengetahuan untuk di-comblang-kan, namun masih tetap dibayang-bayangi "rapot merah" dan mindset statis dan tradisional yang minim inovasi pada sebagian pengurus TBM. Maka dari itu, peneliti tertarik untuk melakukan penelitian untuk mencari hubungan antara knowledge sharing yang merupakan aspek knowledge management yang paling menonjol di Grup FTBM Jawa Barat dengan munculnya Inovasi Pengelola TBM.

\section{METODE PENELITIAN}

Penelitian ini menggunakan metode kuantitatif dengan pendekatan korelasional. Peneliti menggunakan metode kuantitatif dengan pendekatan korelasional karena melalui pendekatan ini dapat diketahui adakah hubungan antara knowledge sharing dengan inovasi pengelola, yang kemudian dapat dicari seberapa besar hubungannya dan bagaimana satu variabel memicu variabel lainnya. Penggunaan metode kuantitatif juga didasari bahwa 
penelitian di FTBM Jawa Barat ini diasumsikan bisa terbukti melalui pengujian teori. Yaitu, pengujian antara teori knowledge management khususnya knowledge sharing dengan inovasi pengelola yang mengharuskan dilihat melalui sisi kuantitatif, yang mana membuat peneliti menggunakan metode kuantitatif dengan pendekatan korelasional.

Populasi pada penelitian ini adalah anggota FTBM Jawa Barat, yang merupakan pengelola TBM yang berdomisili di Jawa Barat. Dari data awal yang didapatkan, terdapat 778 Taman Baca Masyarakat yang resmi terdaftar dan 200 orang yang tergabung dan secara aktif berkomunikasi dalam grup WhatsApp FTBM Jawa Barat. Peneliti menggunakan nonprobability sampling dengan teknik purposive sampling. Jumlah sampel akan dihitung dengan menggunakan Rumus Slovin, menghasilkan jumlah sampel sebanyak 67 orang Pengelola TBM yang memiliki kriteria; (1) Pengelola Aktif TBM; (2) Aktif menggunakan aplikasi media sosial WhatsApp; (3) Aktif dalam melakukan kegiatan knowledge collecting dan/atau donating di Grup FTBM Jawa Barat. Data yang digunakan dalam penelitian ini adalah data primer hasil dari penyebaran angket digital kepada objek penelitian. Peneliti juga menggunakan data sekunder yang bersumber dari wawancara, studi pustaka, dan observasi untuk memperkuat hasil analisis.

Operasionalisasi variabel dalam penelitian ini adalah variabel (X) Knowledge Sharing yang berdasarkan pada teori Knowledge Sharing Process menurut Hooff dan De Ridder (2004), yang memiliki dua sub-variabel yaitu; (X1) Knowledge Donating dan (X2) Knowledge Collecting. Dalam teori ini Bart Van Der Hooff dan Jan A. De Ridder (2004), menjelaskan bahwa, "Knowledge Donating is communicating to others what one's personal intellectual capital is," dan disambung "Knowledge Collecting is consulting colleagues in order to get them to share their intellectual capital."

Variabel (X) Knowledge Sharing kemudian diujikan kepada variabel (Y) Inovasi Pengelola yang berdasarkan pada Type of Innovation menurut Damanpour (1991). Dalam teori ini Damanpour (1991) mengatakan, "Among numerous typologies of innovation advanced in the relevant literature, three have gained the most attention. Each centers on a pair of types of innovation: administrative and technical, product and process, and radical and incremental." Damanpour menjelaskan bahwa dari sekian banyak tipologi inovasi yang ada di dalam berbagai macam literatur, tiga pasang yang paling menyita perhatian: administratif dan teknikal, produk dan proses, serta radikal dan inkremental.

Kemudian data primer yang sudah terkumpul diolah menggunakan SPSS 25 dengan dilakukan analisis statistik deskriptif berupa analisis data responden, analisis data penelitian, kategorisasi kekuatan variabel, dan tabulasi silang. Dilanjutkan dengan analisis statistik inferensial berupa uji korelasi dan pengujian hipotesis. Setelah kedua analisis 
statistik tersebut dilakukan, hasil dari analisis itu kemudian dijabarkan menggunakan kalimat deskriptif, guna mempermudah dalam memahami maksud dari data.

\section{HASIL DAN PEMBAHASAN}

\section{a. Pengelola TBM}

Dalam penelitian ini, sampel yang digunakan sebanyak 67 pengelola TBM di Jawa Barat. Sampel diambil dari data awal yang didapatkan oleh peneliti, sebanyak 778 TBM yang resmi terdaftar dan 200 orang yang tergabung dan secara aktif berkomunikasi dalam Grup WhatsApp FTBM Jawa Barat. Adapun gambaran umum responden dalam penelitian ini, berdasarkan karakteristik dengan bentuk pertanyaan tertutup, adalah sebagai berikut:

Tabel 1. Domisili TBM yang dikelola Responden

\begin{tabular}{cccc}
\hline No. & Domisili TBM yang dikelola & Frekuensi & Persentase \\
\hline 1. & Responden & 8 & $11,9 \%$ \\
2. & Kota Bandung & 1 & $1,5 \%$ \\
3. & Kota Banjar & 5 & $7,5 \%$ \\
4. & Kota Bekasi & 1 & $1,5 \%$ \\
5. & Kota Cimahi & 8 & $11,9 \%$ \\
6. & Kota Depok & 9 & $13,4 \%$ \\
7. & Kabupaten Bandung & 2 & $3 \%$ \\
8. & Kabupaten Bekasi & 1 & $1,5 \%$ \\
9. & Kabupaten Ciamis & 4 & $6 \%$ \\
10. & Kabupaten Cirebon & 2 & $3 \%$ \\
11. & Kabupaten Garut & 5 & $7,5 \%$ \\
12. & Kabupaten Indramayu & 1 & $1,5 \%$ \\
13. & Kabupaten Karawang & 4 & $6 \%$ \\
14. & Kabupaten Kuningan & 2 & $3 \%$ \\
15. & Kabupaten Majalengka & 2 & $3 \%$ \\
16. & Kabupaten Pangandaran & 3 & $4,5 \%$ \\
17. & Kabupaten Subang & 1 & $1,5 \%$ \\
18. & Kabupaten Sukabumi & 2 & $3 \%$ \\
19. & Kabupaten Sumedang & 3 & $4,5 \%$ \\
20. & Kabupaten Tasikmalaya & 3 & $4,5 \%$ \\
& Jumlah & 67 & $100 \%$ \\
\hline
\end{tabular}

Sumber: Pengolahan data oleh Peneliti (2020)

Responden merupakan Pengelola TBM, yang sebagian besar, berasal dari TBM yang berbeda di setiap kabupaten/kota. Responden yang memenuhi kriteria paling banyak berasal dari Kabupaten Bandung, disusul dengan Kota Bandung dan Kota Depok. 
Tabel 2. Lama Mengelola TBM

\begin{tabular}{cccc}
\hline No. & $\begin{array}{c}\text { Sudah berapa lama menjadi } \\
\text { pengelola TBM }\end{array}$ & Frekuensi & Persentase \\
\hline 1. & Kurang dari 1 Tahun & 7 & $10,4 \%$ \\
2. & 2-3 Tahun & 20 & $29,9 \%$ \\
3. & $4-5$ Tahun & 12 & $17,9 \%$ \\
4. & 5 Tahun Lebih & 28 & $41,8 \%$ \\
& Jumlah & 67 & $100 \%$ \\
\hline \multicolumn{4}{c}{}
\end{tabular}

Responden yang memenuhi kriteria sebagai sampel paling banyak merupakan pengelola TBM yang sudah berpengalaman, yaitu lebih dari lima (5) tahun, sebanyak 28 dari 67 orang.

\section{b. Kategorisasi Kekuatan Variabel Penelitian}

Knowledge Donating

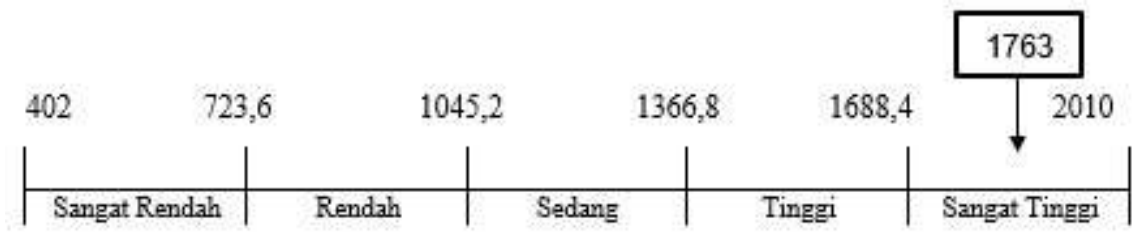

Gambar 1. Garis Kontinum Knowledge Donating

Sumber: Pengolahan data oleh Peneliti (2020)

Secara ideal, skor yang diharapkan untuk jawaban responden terhadap 6 pertanyaan di sub-variabel Knowledge Donating (X1) ini adalah 2010. Namun, dari data di atas, dapat tergambar bahwa persepsi responden mengenai sub-variabel Knowledge Donating (X1) berada pada kategori Sangat Tinggi dengan skor aktual 1763. Setelah diketahui skor ideal dan skor aktual-nya, maka dapat dihitung persentasenya yang kemudian menghasilkan persentase sebesar $87,1 \%$.

Tingginya skor kategorisasi subvariabel Knowledge Donating (X1) dapat diartikan bahwa pengelola TBM sudah mengiyakan, dengan mereka memberi tanggapan positif kepada kegiatan Knowledge Donating, bahwa mereka melakukan kegiatan tersebut dalam kehidupan mereka sehari-hari di Grup FTBM Jawa Barat. Hal ini tercermin dari bagaimana beberapa pengelola TBM membagikan foto dan deskripsi kegiatan yang dilakukan di TBM mereka masing-masing, atau karya yang TBM mereka hasilkan, serta fokus kegiatan yang TBM mereka geluti, seperti; Pak Rohman Gumilar selaku pengelola TBM Bina Kreasi Muda yang menggunakan jejaringnya untuk menghasilkan sebuah online talkshow bersama Ibu 
Tuti selaku pengelola TBM Wijaya Kusuma yang berfokus meningkatkan literasi lingkungan melalui budidaya sayuran hidroponik, dan Pak Sofian Munawar yang membagikan video pada Youtube tentang kegiatan dan pencapaian anggota organisasinya di Ruang Baca Komunitas.

\section{Knowledge Collecting}

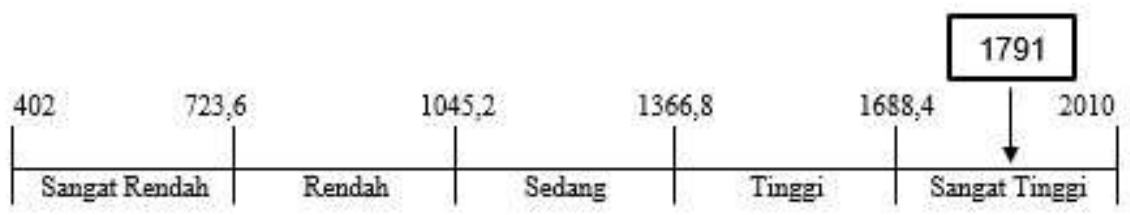

Gambar 2. Garis Kontinum Knowledge Collecting

Sumber: Pengolahan data oleh Peneliti (2020)

Secara ideal, skor yang diharapkan untuk jawaban responden terhadap 6 pertanyaan di sub-variabel Knowledge Collecting (X2) ini adalah 2010. Namun, dari data di atas, dapat tergambar bahwa persepsi responden mengenai sub-variabel Knowledge Collecting (X2) berada pada kategori Sangat Tinggi dengan skor aktual 1791. Setelah diketahui skor ideal dan skor aktual-nya, maka dapat dihitung persentasenya yang menghasilkan persentase sebesar $89,1 \%$.

Tingginya skor kategorisasi sub-variabel Knowledge Collecting (X2) dapat diartikan bahwa pengelola TBM sudah mengiyakan, dengan mereka memberi tanggapan positif kepada kegiatan Knowledge Collecting, bahwa mereka melakukan kegiatan tersebut dalam kehidupan mereka sehari-hari di Grup FTBM Jawa Barat. Hal ini tercermin dari pengelola TBM yang memberikan respon positif ketika ada seorang pengelola TBM lainnya yang membagikan pengetahuannya, seperti; mengucapkan selamat dan mengapresiasi apa yang orang bersangkutan bagikan, kemudian bertanya terkait bagaimana caranya menyelenggarakan acara yang serupa di TBM-nya, dan ikut aktif menonton jika, seperti contoh di atas, Pak Rohman Gumilar membagikan online talkshow beliau dengan tamunya yang selalu berganti setiap minggu.

\section{Knowledge Sharing}

Tabel 3. Rekapitulasi Skor Variabel Knowledge Sharing (X)

\begin{tabular}{ccc}
\hline Knowledge Sharing & Skor & $\%$ \\
\hline Knowledge Donating & 1763 & $87,7 \%$ \\
Knowledge Collecting & 1791 & $89,1 \%$ \\
Total & 3554 & $88,4 \%$ \\
\hline
\end{tabular}

Sumber: Pengolahan data oleh Peneliti (2020) 


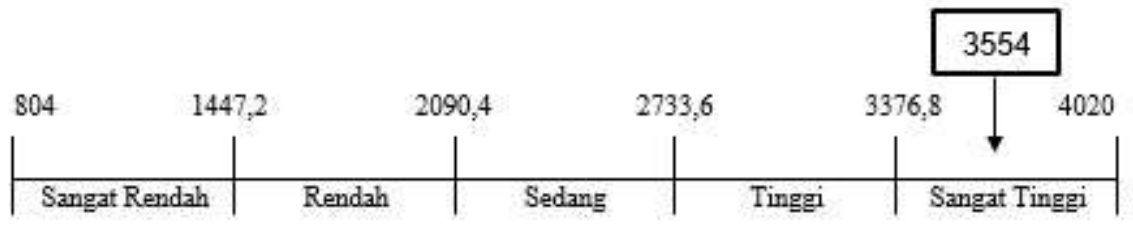

Gambar 3. Garis Kontinum Knowledge Sharing

Sumber: Pengolahan data oleh Peneliti (2020)

Secara ideal, skor yang diharapkan untuk jawaban responden terhadap 12 pertanyaan di variable Knowledge Sharing (X) ini adalah 4020. Namun, dari data di atas, dapat tergambar bahwa persepsi responden mengenai variabel Knowledge Sharing (X) berada pada kategori Sangat Tinggi dengan skor aktual 3554 Setelah diketahui skor ideal dan skor aktual-nya, maka dapat dihitung persentasenya yang menghasilkan persentase sebesar $88,4 \%$.

Tingginya skor kategorisasi variabel Knowledge Sharing (X) dapat diartikan bahwa pengelola TBM sudah mengiyakan, dengan mereka memberi tanggapan positif kepada kegiatan Knowledge Donating dan Collecting, bahwa mereka melakukan kegiatan tersebut dalam kehidupan mereka sehari-hari di Grup FTBM Jawa Barat. Hal ini semakin menguatkan kategorisasi baik untuk sub-variabel Knowledge Donating (X1) dan Knowledge Collecting (X2). Selaras dengan apa yang terjadi di lapangan, bahwa kegiatan Knowledge Sharing sudah dipraktikan secara informal antara satu pengelola TBM dengan pengelola TBM lainnya.

Dilihat dalam konteks Knowledge Management secara utuh, Knowledge Sharing di FTBM Jawa Barat memang yang paling menonjol. Menurut teori Knowledge Management dari du Plessis (2007), bahwa ada tiga dimensi dari Knowledge Management, Knowledge Creation, Sharing, dan Leverage. Dimensi Knowledge Creation ini ada dan dilakukan di FTBM Jawa Barat, yang secara riil dilakukan dalam kegiatan; membuat buku yang berisi pengalaman, kesan, dan ilmu yang didapat pada Kemah Literasi Jawa Barat yang merupakan acara besar milik FTBM Jawa Barat. Kemah Literasi Jawa Barat tahun 2019 menghasilkan sebuah buku berjudul; Pamatri Literasi, yang diterbitkan dan dijual secara mandiri.

Dimensi Knowledge Leverage, atau bagaimana cara untuk menggunakan pengetahuan yang sudah ada, juga sudah ada dan dilakukan di FTBM Jawa Barat. Dilakukan secara riil melalui website mereka yang beralamat di pamatriliterasi.com, merupakan sebuah media berita yang memiliki pemimpin redaksi, reporter, dan editor. Melalui berita dan tulisan yang berada di website itu, pengetahuan yang sudah tercipta dan menjadi perbincangan di dalam organisasi FTBM Jawa Barat dipublikasikan ke dunia luar. Berita dan tulisan yang dipublikasikan dibuat ketika ada acara-acara tertentu, seperti; Kemah Literasi 
Jawa Barat, rapat rutin pengurus FTBM, pengalaman pengelola dalam menggeluti suatu bidang, resensi buku yang sudah dibaca oleh pengelola TBM. Namun, untuk pembicaraan atau kegiatan knowledge donating dan collecting di dalam Grup FTBM Jawa Barat seperti berbagi pengalaman dalam melaksanakan kegiatan dan mengelola TBM, masih belum diangkat menjadi berita dan tulisan yang dapat dipublikasikan. Dari ketiga hal itu, dimensi Knowledge Sharing menjadi kegiatan informal yang tanpa disadari sangat sering dilakukan namun kurang mendapat perhatian dan pengelolaan khusus dari pihak pengurus FTBM Jawa Barat.

\section{Inovasi Pengelola}

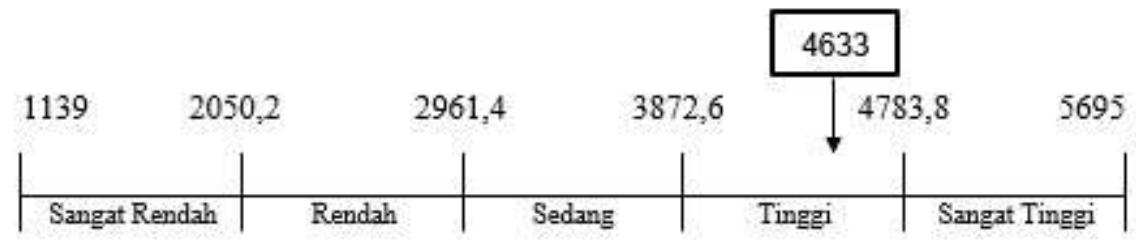

Gambar 4. Garis Kontinum Inovasi Pengelola

Sumber: Pengolahan data oleh Peneliti (2020)

Secara ideal, skor yang diharapkan untuk jawaban responden terhadap 17 pertanyaan di variabel Inovasi Pengelola (Y) ini adalah 5695. Namun, dari data di atas, dapat tergambar bahwa persepsi responden mengenai variabel Inovasi Pengelola (Y) berada pada kategori Tinggi dengan skor aktual 4633. Setelah diketahui skor ideal dan skor aktualnya, maka dapat dihitung persentasenya yang menghasilkan persentase sebesar $81,4 \%$.

Tingginya skor kategorisasi variabel Inovasi Pengelola (Y) dapat diartikan bahwa pengelola TBM memang berinovasi di dalam kegiatan dan TBM-nya itu sendiri. Menurut Damanpour (1991), tipe inovasi sendiri ada tiga pasang, namun dalam penelitian ini, peneliti hanya menggunakan satu pasang; Product dan Process Innovation. Tipe inovasi Product dan Process ini juga yang paling terlihat dalam aktivitas keseharian FTBM Jawa Barat.

Untuk product innovation sendiri, sudah cukup banyak yang tercipta oleh pengelola TBM. Tercermin dari berbagai kegiatan dan layanan yang dibagikan di Grup FTBM Jawa Barat, seperti; Online Talkshow dari TBM Bina Kreasi Muda yang mengupas tentang bagaimana masyarakat rural bisa berkontribusi membangun tingkat literasi di masyarakat sekitar, atau Khataman Buku oleh Komunitas Literasi Senja yang membahas dan mengajak masyarakat umum untuk membaca dan menyelesaikan buku-buku sastra Indonesia dengan metode yang menarik. Metode ini juga diadopsi oleh FTBM Jawa Barat dengan membuat 
sebuah grup khusus bernama "Reading Group" yang setiap hari senin berkomunikasi untuk membaca beberapa novel, antara lain novel Arus Balik karangan Pramoedya Ananta Toer.

Untuk process innovation, pengelola TBM sendiri masih sedikit tertutup soal ini. Banyak dari pengelola TBM dengan senang hati membagikan produk inovasinya, namun masih sedikit yang menyampaikan dengan jelas proses terciptanya inovasi. Dimulai dari hal kecil namun penting; Standar Operasional Prosedur (SOP), pengelola TBM masih mengiyakan SOP dalam bentuk lisan dan jarang sekali terdapat pembahasan mengenai SOP dan pengembangannya di Grup FTBM Jawa Barat. Hal ini tidak bisa digeneralisasi tentunya kepada setiap pengelola TBM dan setiap hal yang berhubungan dengan proses terciptanya inovasi. Masih ada pengelola TBM yang mau berbagi secara terbuka tentang proses terciptanya inovasi, seperti Panti Baca Ceria yang membagikan kegiatan Nobar Serentak (Nonton Bareng Serentak) film dokumenter "Beta Mau Jumpa" hasil kerja sama CRCS UGM dengan berbagai institusi lainnya, yang kemudian ditanya oleh pengelola TBM lain tentang bagaimana caranya Panti Baca Ceria bisa mendapatkan koneksi dengan CRCS UGM, dan dijelaskan oleh pemilik Panti Baca Ceria bagaimana cara berkoneksi dengan mereka.

\section{c. Keterkaitan Lama Mengelola TBM dengan Variabel Penelitian}

Setelah dilakukan pengolahan data untuk mengukur kekuatan variabel penelitian, kemudian peneliti melakukan analisis tabulasi silang. Analisis tabulasi silang sendiri peneliti lakukan antara karakteristik pengelola TBM dengan variabel penelitian. Karakteristik pengelola TBM yang dihimpun dalam penelitian ini adalah: lama mengelola TBM sedangkan variabel penelitian pada penelitian ini adalah: Knowledge donating (X1), knowledge collecting (X2), knowledge sharing $(\mathrm{X})$, dan inovasi pengelola $(\mathrm{Y})$.

Pengujian pertama, kedua, dan ketiga secara berurutan dilakukan antara lama mengelola TBM dengan knowledge donating (X1), collecting (X2), dan sharing (X3). Hasil tabulasi silang menggunakan rumus chi-square ini menunjukkan tidak adanya keterkaitan antara lama mengelola TBM dengan knowledge donating (X1), collecting (X2), dan sharing (X3). Hal ini bisa dilihat karena nilai Asymptotic Significance (2-Sided)-nya secara berurutan, sebesar 0,391; 0,700; dan 0,204 yang mana lebih besar dari $=0,05$. Hal ini dapat diartikan bahwa kegiatan knowledge donating (X1), collecting (X2), dan sharing (X3) sudah bisa dilakukan oleh pengelola TBM tanpa memandang pengalamannya dalam mengelola TBM.

Hal berbeda tampak ketika peneliti melakukan pengujian keempat antara lama mengelola dengan inovasi pengelola (Y). Hasil tabulasi silang menggunakan rumus chisquare ini menunjukan adanya keterkaitan antara lama mengelola TBM dengan inovasi 
pengelola (Y). Hal ini bisa dilihat karena nilai Asymptotic Significance (2-Sided)-nya sebesar 0,005, dan lebih kecil dari $=0,05$. Hal ini dapat diartikan bahwa inovasi pengelola TBM (Y) lebih terlihat dan lebih bisa dihasilkan oleh pengelola TBM yang pengalaman mengelolanya terbilang cukup lama, yaitu 4-5 tahun dan lebih dari 5 tahun.

\section{d. Hubungan antara Knowledge Sharing dengan Inovasi Pengelola}

Knowledge Sharing dengan Inovasi Pengelola

Knowledge sharing $(\mathrm{X})$ dengan variabel inovasi pengelola $(\mathrm{Y})$ memiliki nilai koefisien korelasi sebesar 0,526 yang termasuk pada tingkat hubungan berkategori sedang. Hubungan berkategori sedang antara variabel knowledge sharing (X) dengan variabel inovasi pengelola $(\mathrm{Y})$, mengartikan bahwa secara keseluruhan kegiatan membagikan dan mengumpulkan informasi atau pengalaman pengelola Taman Baca Masyarakat dalam mengelola TBM yang menyangkut berbagi informasi dan pengalaman terkait program/layanan yang akan atau sudah diselenggarakan TBM, setidaknya cukup mampu memicu terciptanya inovasi pengelola untuk membuat dan/atau menerapkan hal yang serupa di TBM.

Analisis korelasi dapat dilanjutkan dengan menghitung koefisien determinasi, diperoleh hasil koefisien determinasinya sebesar 27,66\%. Hal ini berarti bahwa hubungan knowledge sharing $(\mathrm{X})$ dengan inovasi pengelola $(\mathrm{Y})$ sebesar $27,66 \%$ dan sisanya sebesar 72,34\% ditentukan oleh faktor lain di luar penelitian ini. Penerapan knowledge sharing di organisasi/perusahaan memang sangat memberikan keuntungan, yaitu meningkatkan kemampuan dalam melihat kesempatan dengan lebih cepat sehingga penciptaan inovasi juga akan lebih cepat tanpa menghabiskan banyak biaya operasional (Nawawi, 2012). Hal ini juga didukung dari penelitian Maulana (2018), yang mengatakan bahwa hasil analisis data menunjukkan knowledge sharing mempunyai pengaruh yang signifikan terhadap kinerja inovasi. Namun hasil cukup berbeda dialami oleh organisasi nonprofit seperti FTBM Jawa Barat.

Proses Knowledge sharing di Grup FTBM Jawa Barat sendiri berfokus pada pengetahuan pribadi yang kemudian di-donate secara mandiri dan kemudian dikumpulkan oleh orang-orang yang berkesempatan melihat chat itu sebelum akhirnya "tenggelam" oleh chat lain yang mungkin bukan merupakan pengetahuan. Kegiatan knowledge sharing di sini tidak memiliki seorang makelar di mana arus informasi tidak ada yang memicu, memfilter, dan kemudian menyimpan informasi itu secara terstruktur. Menyebabkan knowledge sharing hanya mengambil porsi kurang lebih seperempat dari faktor yang menentukan terciptanya inovasi pengelola. 
Namun, hal ini selaras dengan teori dari du Plessis (2007) tentang Knowledge management yang mengatakan bahwa, "Knowledge Management assists in creating tools, platforms and processes for tacit knowledge creation, sharing and leverage in the organization, which plays an important role in the innovation process." Dalam teori tersebut dikatakan bahwa dalam proses inovasi dibutuhkan peran knowledge creation, knowledge sharing, dan knowledge leverage yang secara bersama-sama berperan penting di dalam proses inovasi.

\section{Knowledge Donating dengan Inovasi Pengelola}

Sub-variabel knowledge donating (X1) dengan variabel inovasi pengelola (Y) memiliki nilai koefisien korelasi sebesar 0,418 yang termasuk pada tingkat hubungan berkategori sedang. Hubungan berkategori sedang antara sub-variabel knowledge donating (X1) dengan variabel inovasi pengelola (Y) TBM di FTBM Jawa Barat, mengartikan bahwa kegiatan berbagi informasi atau pengalaman dalam mengelola TBM, kemudian membagikan program/layanan yang akan atau sudah diselenggarakan setidaknya cukup mampu memicu terciptanya inovasi pengelola TBM lainnya, untuk membuat dan/atau menerapkan hal yang serupa di TBM-nya.

Analisis korelasi dapat dilanjutkan dengan menghitung koefisien determinasinya, diperoleh hasil koefisien determinasinya sebesar 17,47\%. Hal ini berarti bahwa hubungan knowledge donating $(\mathrm{X} 1)$ dengan inovasi pengelola $(\mathrm{Y})$ sebesar 17,47\% dan sisanya sebesar 82,53\% ditentukan oleh faktor lain di luar penelitian ini.

Kegiatan knowledge donating di Grup FTBM Jawa Barat ini juga sudah bagus, namun masih kurang beragam. Selaras dengan data statistik yang didapatkan, hubungan knowledge donating dengan inovasi pengelola tidak sampai satu perlima. Hal ini mungkin disebabkan karena pengelola TBM yang mau membagikan pengetahuannya jumlahnya masih sedikit dan orangnya itu-itu saja. Faktor inilah yang mungkin membuat inovasi pengelola agak sulit tercipta dari sub-variabel knowledge donating.

Knowledge Collecting dengan Inovasi Pengelola

Hubungan sub-variabel knowledge collecting (X2) dengan variabel inovasi pengelola (Y) memiliki nilai koefisien korelasi sebesar 0,457 yang termasuk pada tingkat hubungan berkategori sedang. Hubungan berkategori sedang antara sub-variabel knowledge collecting (X2) dengan variabel inovasi pengelola (Y) TBM di FTBM Jawa Barat, mengartikan bahwa kegiatan mengumpulkan informasi atau pengalaman pengelola lainnya dalam mengelola TBM mereka, kemudian mengumpulkan dan menelaah informasi terkait program atau layanan yang akan atau sudah diselenggarakan TBM lain, setidaknya cukup mampu 
memicu terciptanya inovasi pengelola untuk membuat dan/atau menerapkan hal yang serupa di TBM.

Analisis Korelasi dapat dilanjutkan dengan menghitung koefisien determinasinya, diperoleh hasil koefisien determinasinya sebesar 20,88\%. Hal ini berarti bahwa hubungan knowledge collecting (X2) dengan inovasi pengelola (Y) sebesar 20,88\% dan sisanya sebesar $79,12 \%$ ditentukan oleh faktor lain di luar penelitian ini. Sub-variabel knowledge collecting lebih banyak mengambil porsi ketimbang sub-variabel knowledge donating. Hal ini selaras dengan apa yang terjadi di lapangan, di mana pengelola Taman Baca Masyarakat di Grup FTBM Jawa Barat lebih senang menanggapi atau bertanya ketimbang membagikan apa yang mereka punya. Kemudahan dalam kegiatan knowledge collecting mungkin menjadi salah satu alasan mengapa hal ini bisa terjadi, hanya bermodalkan keinginan untuk belajar maka kegiatan knowledge collecting sangat mudah untuk dilakukan. Membuat pengelola TBM lainnya nyaman, untuk belajar dalam diam, namun masih aktif jika dibutuhkan.

\section{SIMPULAN}

Berdasarkan hasil dari penelitian dan pembahasan, penelitian ini dapat disimpulkan menjadi beberapa poin. Poin pertama, aspek knowledge donating dan knowledge collecting secara simultan memiliki hubungan dengan terciptanya inovasi pengelola. Dari dua aspek tersebut, meskipun tidak optimal menjadi pemicu terciptanya inovasi pengelola, namun knowledge donating dan knowledge collecting memiliki peran penting dalam proses knowledge management secara utuh. Hal ini dapat terlihat dari betapa dinamisnya proses knowledge sharing (berbagi pengetahuan) di FTBM Jawa Barat, yang sayangnya kurang dikelola dengan maksimal, tanpa ada; broker (makelar), catatan tertulis, dan publikasi yang memadai.

Selanjutnya dalam aspek knowledge donating memiliki hubungan dengan terciptanya inovasi pengelola. Pengelola TBM di FTBM Jawa Barat melakukan kegiatan berbagi pengetahuan yang berbentuk informasi atau pengalaman dalam mengelola TBM, yang secara rinci berupa foto dan/atau deskripsi program atau layanan yang pengelola bagikan di Grup WhatsApp FTBM Jabar, seperti; Online Talkshow oleh TBM Bina Kreasi Muda, dan Khataman Buku oleh Komunitas Literasi Senja. Kegiatan tersebut menjadi terciptanya inovasi yang digagas oleh pengelola. Terakhir, dalam aspek knowledge collecting, aspek ini juga memiliki hubungan dengan terciptanya inovasi pengelola. Pengelola TBM di FTBM Jawa Barat mengumpulkan pengetahuan yang secara rinci berbentuk informasi atau pengalaman dalam mengelola TBM, seperti bertanya terkait tips 
dan trik agar acara Nobar Serentak yang dilakukan oleh Panti Baca Ceria dengan CRCS UGM dapat terselenggara. Hal ini menjadi bukti terciptanya inovasi pengelola.

Saran yang dapat penulis berikan bagi penelitian selanjutnya takni pengujian knowledge management secara keseluruhan atau variabel-variabel lainnya yang mungkin mengambil peran dalam terciptanya inovasi pengelola TBM. Dengan demikian, melalui penelitian lanjutan tersebut, dapat diketahui komposisi unsur pembentuk terciptanya suatu inovasi, khususnya di Forum TBM. Hal ini berguna bagi TBM agar memiliki tata cara dan alur yang jelas dalam penciptaan inovasi.

\section{Kontribusi Pada Keilmuan}

Penelitian ini merupakan kajian dalam bidang knowledge management yang mengkaji tentang knowledge sharing. Penelitian ini juga berkaitan dengan bidang literasi secara umum yang direpresentasikan oleh objek penelitian ini. Hasil penelitian ini dapat menjadi dasar untuk penelitian selanjutnya atau penelitian bidang sejenis mengenai seberapa besar hubungan knowledge management secara umum dan knowledge sharing secara khusus dengan inovasi.

\section{Pernyataan Minat Kajian}

Peneliti bernama Yoshua Gilang Pratama memiliki minat kajian dalam bidang knowledge management secara umum dan knowledge sharing secara khusus. Peneliti bernama Sukaesih memiliki minat kajian dalam bidang literasi informasi.

\section{Kontribusi Peneliti}

Peneliti dengan nama Yoshua Gilang Pratama melakukan survei, wawancara, pengumpulan data, serta analisis data. Peneliti dengan nama Sukaesih memberikan arahan serta koreksi dalam analisis data serta teori yang digunakan.

\section{Kontribusi Pihak Lain}

Ucapan terima kasih juga peneliti sampaikan kepada Kang Taufik "Nero" Abdullah selaku ketua FTBM Jawa Barat periode 2017-2021 dan kepada Pak Rohman Gumilar selaku pembimbing dan penghubung di lapangan antara peneliti dengan anggota FTBM Jawa Barat lainnya.

\section{DAFTAR PUSTAKA}

Alaei, A., Shafaee, J., Ariana, A., \& Maghvan, T. (2012). The role of knowledge management in created organizational innovation. Journal of Basic and Applied Scientific Research, 2(2), 1136-1141. Retrieved from http://www.textroad.com/pdf/JBASR/J. Basic. Appl. Sci. Res., 2(2)1136-1141, 2012.pdf

Choi, S. (2014). Learning orientation and market orientation as catalysts for innovation in nonprofit organizations. Nonprofit and Voluntary Sector Quarterly, 43(2), 393-413. https://doi.org/10.1177/0899764012465491

Damanpour, F. (1991). Organizational innovation: a meta-analysis of effects of determinants and moderators. Academy of Management Journal, 34(3), 555-590. 
https://doi.org/10.2307/256406

$\mathrm{Du}$ Plessis, M. (2007). The role of knowledge management in innovation. Journal of Knowledge Management, 11(4), 20-29. https://doi.org/10.1108/13673270710762684

Firmaiansyah, Danang. (2014). Pengaruh berbagi pengetahuan terhadap kinerja karyawan melalui inovasi. Jurnal Ilmu Manajemen, 2(1), 128-39. Retrieved from https://core.ac.uk/download/pdf/230760645.pdf

Hidayanto, J., Rahardjo, T. J., \& Daman. (2012). Upaya meningkatkan minat baca masyarakat melalui taman bacaan masyarakat area publik di kecamatan ungaran timur kabupaten semarang. In Journal of Non Formal Education and Community Empowerment, 1(2), 33-39. Retrieved from https://ib.unnes.ac.id/17155/

Aulawi, H., Govindaraju, R., Suryadi K., \& Sudirman, I. (2009). Hubungan knowledge sharing behavior dan individual innovation capability. Jurnal Teknik Industri, 11(2), 174-187. $\quad$ Retrieved from http://puslit2.petra.ac.id/ejournal/index.php/ind/article/view/17686

Johannessen, J. A., Olsen, B., \& Olaisen, J. (1999). Aspects of innovation theory based on knowledge-management. International Journal of Information Management, 19(2), 121-139. Retrieved from https://doi.org/10.1016/S0268-4012(99)00004-3

Maulana, Fajar, Sularso R. A., \& Titisari P. (2018). Analisis pengaruh knowledge sharing dalam penerapan sistem manajemen mutu ISO 9001:2008 terhadap kinerja inovasi dan kinerja karyawan. Jurnal Manajemen Dan Kewirausahaan, 6(1), 57-69. Retreived from http://jurnal.unmer.ac.id/index.php/jmdk/article/view/2045/1535

Miller, John W., \& Michael C. McKenna. (2016). World literacy: how countries rank and why it matters. New York and London: Routledge.

Nawawi, Ismail. (2012). Manajemen pengetahuan (knowledge management). Bogor: Ghalia Indonesia.

Pramudyo, Nur, G., Ilmawan, M. R., Azizah, B., Anisah, M., \& Deo, Yanuar. (2018). Inovasi kegiatan taman bacaan masyarakat (TBM). Lentera Pustaka: Jurnal Kajian Ilmu Perpustakaan, Informasi Dan Kearsipan, 4(1), 29. Retrieved from https://ejournal.undip.ac.id/index.php/lpustaka/article/view/17332.

Suwanto, S. A. (2019). Pengelolaan TBM sebagai sarana meningkatkan minat baca masyarakat. Anuva, 1(1), 19-32. https://doi.org/10.14710/anuva.1.1.19-32

Van Den Hooff, B., \& Ridder, J. A. (2004). Knowledge sharing in context: the influence of organizational commitment, communication climate and CMC use on knowledge sharing. Journal of Knowledge Management, 8(6), 117-130. https://doi.org/10.1108/13673270410567675

Yeşil, S., Koska, A., \& Büyükbeşe, T. (2013). Knowledge sharing process, innovation capability and innovation performance: an empirical study. Procedia - Social and Behavioral Sciences, 75, 217-225. https://doi.org/10.1016/j.sbspro.2013.04.025 